\title{
Polaroid into digital: Technology, cultural form, and the social practices of snapshot photography
}

At its Annual Meeting in 1991, the Polaroid Corporation distributed, as part of its Shareholders' package, a loose sheet devoted to 'Photo-Document Integration'. Beneath an image depicting a Polaroid camera, a Polaroid print, a scanner, a computer, and a laser printer, the document details how in the future imagedependent businesses' will rely on 'converting ... images into digital data files that can be easily integrated with other computer data.' (see Figure 1) ${ }^{1}$ By any measure it is a melancholy document. It successfully predicts the technological future but cannot see that the full arrival of this future will render the Polaroid image obsolete. In the new media landscape so accurately sketched out by the document, melancholics are of course thin on the ground: one of the pleasant, even narcotic, effects of new media, for those who have access to them, is a forgetfulness about the once new older forms they have replaced. Indeed, in order for any technology to be acclaimed as a novelty, this forgetfulness is an absolute prerequisite. It is the model of progress implicit in this forgetting that caused Walter Benjamin, in his essay 'Surrealism,' to follow Andre Breton in turning his attention to the 'outmoded,' to 'objects that have begun to be extinct,' to once-fashionable things 'when the vogue has begun to ebb from them' $(1999,210)$. Polaroid photography is one of those objects on the verge of extinction: the company stopped making film at its Enschede plant in the Netherlands at the end of 2008, and supplies were expected to run out entirely by the 
end of 2009. It deserves critical attention now, at the moment of its imminent disappearance, not in the form of a requiem, but because it retroactively sheds light on the newer technologies that have apparently surpassed it.

While it is hard to argue against the prevailing wisdom that chemically-based photography has been displaced by electronically-based digital image-making, what that change means is still very much up for grabs. There has been no shortage of attempts to tackle this problem, with Tom Gunning most recently, and convincingly, making the case that the shift from chemical to digital has not radically transformed the basic status of the photographic image. Addressing the oft-noted fact that digital photographs can be easily and quickly manipulated, he claims that this does not ultimately have a profound effect on their indexicality $(2008,24)$, nor on the 'nearly inexhaustible visual richness' of the photographic (37). He concludes that 'Like...earlier transformations in photographic history, the digital revolution will change how photographs are made, who makes them, and how they are used - but they will still be photographs' (38). The case he makes is compelling and should be influential in debates on what digital alteration means for the ontology of the photographic image. However, as he admits, he has set aside in his argument the questions of 'how photographs are made, who makes them, and how they are used'. But can these questions be legitimately set aside, and can images really be so easily separated from practices of image-making? Peter Osborne firmly rejects any attempts to ontologize the photographic on the grounds that any idea of a founding unity of 
the photographic' involves the 'reductive identification of a cultural form with a technology' $(2003,68)$. According to Osborne, we cannot simply isolate photography from its social practices, because it will always be an 'unstable unit[y] of material form and social use' (65). In other words, it is the wrong question to ask whether the 'photographic' has changed, since it does not exist autonomously from its manifestations as cultural form.

Taking up the case of Polaroid photography then, this article will argue that the obsolescence of a technology does not necessarily mean the absolute passing of a cultural form, but rather the modification of already existing practices. In considering Polaroid and digital photography together, it has two main aims:

1) To shift debates on digital photography away from their main emphasis on manipulation or alteration of the image. This emphasis has served to isolate images as images alone, severed from their practices of making, an issue which is more difficult to avoid with Polaroid photography, with its distinctive form of image-making.

2) To identify a distinctive snapshot praxis. Polaroid prints, with their white borders, strict size restrictions, and lack of a negative are clearly different materially from other kinds of photograph, and from amateur digital photography. However, the speed with which the image appears, and the absence of a darkroom or other conventional means of image development are features Polaroid photography shares with digital snapshot photography: 
an examination of the latter through the prism of the former allows us to see better what is at stake in the new techno-cultural form, but also where its absolute novelty must be qualified.

Before these issues are taken up, though, it is necessary to give a brief outline of the development and decline of Polaroid photography.

\section{The end of 'one-step' photography}

The year in which Polaroid distributed to its shareholders the 'Photo-Document Integration' information sheet also marked the death of Edwin Land, inventor of the Polaroid photographic process, and founder, in 1937, of the Polaroid Corporation. The information sheet illustrates a process that would come to be described as 'convergence,' but to Edwin Land it would no doubt have been anathema, for it undoes the main principle of image-making that he promoted at Polaroid. When Land announced in 1947 the invention of Polaroid photography, he dubbed it 'onestep' photography, because it eliminated a number of steps between exposure and final print, most obviously the process of chemical development of a negative into a positive image in a photo-lab. In an essay describing the process, Land emphasised just how many 'steps' his invention had compressed into one by listing the sequence of 'Conventional Processing': 'Expose, develop the negative, rinse, fix, wash, dry, expose the positive through the negative, develop, rinse, fix, wash, dry' (1947, 62). 
In these first versions of 'instant' photography, the camera operator was still responsible for timing the development of the film, pulling it out of the camera to burst the 'pod' of developing reagent, and peeling the useless negative away from the finished print. Only after twenty-five more years of research in chemistry, optics and electronics, did Land achieve his ultimate aim, in the form of SX-70 technology, which mechanically ejects from the camera a white-bordered image that develops before the eyes of its user. For those who remember Polaroid picture-taking, it is usually this second generation of cameras that define the experience of Polaroid use. Having dispensed with every activity on the part of the photographer except loading the film and releasing the shutter, Land was now satisfied that Polaroid had achieved 'absolute one-step photography'. As he put it, 'When you press the electric button a whole series of operations happens in the camera; by the end of one and a quarter seconds after the electric shutter button is touched the camera has done its part, the film is ejected and a whole series of events occur within the film' $(1974,338)$. Land numbers the steps reduced to one at between 'two hundred and five hundred, depending on how you choose to fractionate them' (338). To actually add steps between the pressing of the shutter button and the production of an image, as is done in 'Photo-Document Integration', could only be a step backwards from Land's point of view.

Cheaper versions of SX-70 technology were made available through the 1970s, and one of them, the 'One-Step', became the world's most widely sold camera in the early 
1980s (Columbus 1999, 119). After Kodak, Polaroid was now securely the world's second largest manufacturer of amateur photographic equipment, fiercely protecting its numerous patents ${ }_{2}$ and defeating Kodak_in court for infringement of them. Into the 1980s and 1990s it successfully maintained a monopoly over a single lucrative process: the provision of a completed image shortly after the exposure of a film. But the translation of images into a binary code put paid to that dominance and ultimately ensured the superseding of the original 'instant photography' and the decline of the company that nurtured it. _The slow poison of 'new media' worked throughout the 1990s on Land's invention, and Polaroid filed for bankruptcy protection in October 2001. It was then bought in August 2002 by a Chicago investment group, One Equity Partners, which sat on its acquisition, while Polaroid continued to produce and sell cameras and film. One Equity then sold it on to Petters Group Worldwide in 2005. ${ }^{2}$ In an interview with the New York Times in October 2005, the new chairman of Polaroid under Petters, Stewart L. Cohen, claimed that 'Polaroid still has a multimillion-dollar instant film business that is still profitable,' but conceded later in the interview that 'the statistics say there's not much life left in the business. People just aren't buying a lot of instant cameras' (Deutsch 2005). Indeed, he was keener to promote Polaroid's new brand image as a maker of Plasma TVs and portable DVD players. Or rather than maker, marketer, of these products, since Cohen makes clear in the interview that 'The most important thing is that Polaroid keep shifting its paradigm away from manufacturing, with its huge fixed costs' (Deutsch 2005). In other words, a company whose business identity had historically been based on 
inventing and selling new products that no other company made, and was once known for its 'maverick laboratory-based corporate structure,' (Martin Kao 1999, 13) had become just another out-sourcing subsidiary in a crowded marketplace. On February 8, 2008 Polaroid/Petters announced that it would be permanently discontinuing the manufacture of instant film. In late 2008 Tom Petters, chair of Polaroid's new parent company, was arrested for financial fraud, and Polaroid, filing for a second time for bankruptcy protection, was purchased in April 2009 by a joint US-Canadian investment group in a fire-sale of Petters' assets.

'Polaroid' still exists, then, and still trades in the field of visual technologies, but for all intents and purposes it is no longer the same entity that was formed in 1937 to manufacture polarizing filters and sold the first 'one-step' camera in a Boston department store in 1948. The company was in fact actively researching computer graphics in the 1980s, and early in developments of digital photographic technology, but perhaps held out too many hopes for the continued importance of the chardcopy,' as the 'Photo-Document Integration' memo attests. ${ }^{3}$ Most recently, it introduced in March 2009 a small format 'instant mobile printer', the Polaroid PoGo, but high cost and poor image quality have thus far ensured poor sales. More to the point, the PoGo adds steps to the process of amateur image-making rather than taking them away, as Polaroid photography always set out to do.

\section{Critical context: the Photoshop cul-de-sac}


Polaroid's demise at the hands of digital photography has been noted by many; indeed, the observation is usually extended to all chemically-based photographic technologies. The exact details vary, but it would be difficult to find someone who did not agree in principle with Graham Clarke's observation that

Despite the difference between a daguerreotype and a polaroid print, the photograph has always been based on a chemical process. Images are now being generated on the basis of electronic processes which fundamentally change the terms by which we relate to the photograph, retrieve, experience, and read it. $(1997,218-20)$

Perhaps in 1997 it was too early to tell, but Clarke did not go on to elaborate how exactly things had changed, how 'the terms by which we relate to the photograph, retrieve, experience, and read it' had been modified by digitalisation. Precisely what properties distinguish the old technology from the new one? In what way do these differences impact on the uses of the media? Do they generate new social practices or adapt to existing ones? In the 1990s a number of analysts attempted to answer these questions in relation to the advent of digital photography. While the debate was animated, the results were mixed, largely because of a fixation on the question of image manipulation or alteration._However, asking these questions of popular snapshot photography, and Polaroid photography in particular, helps to reorient and reinvigorate the debate, partly because of Polaroid's difference from other forms of snapshot photography, but especially because of some key similarities between the 
instantaneously produced digital image and the Polaroid 'instant image' first produced in the 1940s. While advances in new media inevitably attract the most attention for their high-end applications, the_lower end of snapshot culture also deserves attention.

As was noted earlier with regards to Tom Gunning's recent intervention, discussion on digital photography, especially at its height in the mid- to late- 1990s, tended to focus disproportionately on a single issue: the manipulation of images. _Andrew Murphie and John Potts nicely summarize what is generally thought to be at stake in the advent of digital photography:

Photography enjoyed ... a truth effect in the nineteenth century and for much of the twentieth; this authentic fit between things and photographs has been undermined by the potential for manipulation residing in digital image-making. Digital photography challenges accepted notions of representation in ways which some find disturbing, yet others find liberating....image scanners and software programs enabling the easy manipulation of digitised images....The widespread use in the 1990s of digital cameras in journalism removed the guarantee of truth held in the photographic negative. (2003, 75-6)

As Murphie and Potts suggest, for some early commentators, advances in digital image-making, far from being unsettling, were a welcome development, an opportunity to break with the referent once and for all. One of the key celebrants, W.J.T. Mitchell, announced that 
Photographs....were comfortably regarded as casually generated truthful reports about things in the real world....But the emergence of digital imaging has irrevocably subverted these certainties, forcing us to adopt a far more wary and more vigilant interpretive stance....Today, as we enter the post-photographic era, we must face once again the ineradicable fragility of our ontological distinctions between the imaginary and the real. $(1992,225)$

Just as Murphie and Potts hedge their bets when invoking the 'truth-effect' of conventional photography, so Mitchell, using the passive voice (photographs 'were...regarded') distances himself from the notion that photographs ever were in fact 'truthful reports about things in the real world.' Nevertheless, this sort of qualification did not prevent him from being chastised on all sides for the supposed naivety with which he welcomed the digital 'revolution.' In fact, for a while it was almost obligatory to take him to task in subsequent commentary on digital photography, such was the preoccupation in the mid-1990s with the effect of manipulation, or 'Photoshopping' on the 'truth' of the image. ${ }^{4}$ _As a result, a good deal of energy was expended on pointing out the obvious fact that chemically-based photos had always been manipulated, so there was nothing particularly new about digital touching-up. ${ }^{5}$ Equally, necessary reminders were given that photographic images, just like digital images, are far from unmediated in their relation to the world; that they are coded and therefore read, that they are selected and framed and given meaning by context and caption, that an uncritical positivism lies behind the notion 
that photos are evidence, and that in any case realism is an elaborate ideological construct and not a transparent window onto reality. ${ }^{6}$ At the end of all these proofs, the conclusion usually drawn is again cautiously of the 'nothing particularly new' school and contra Mitchell's confident assertion that the digital image is a revolutionary new development in the image-world.

The caution and scepticism with which these commentators approach digital photography is shared by much writing on digital culture coming out of the academy. There are two main reasons for this sober stance: 1) a perceived need to act as a balance to the speculative flights of fancy of the popular press and specialist digital hype-merchants; 2) a pulling back from early enthusiasms emanating from the academy on the utopian possibilities of new technologies, before the dot.com bust and before the dreary realities of white-collar e-mail serfdom became clear. Indeed, it is hard these days to find an academic article or book on digital culture that does not distance itself from 'the cacophonous new media rhetoric' (Everett and Caldwell 2003 , xi) or warn that 'It is no longer credible...to imagine that digital media is somehow marked by a radical break with traditional media practices' (Caldwell 2003, 130). One of the best contributors to this genre, Jeffrey Sconce, reflects wryly on the failures of digital culture to fulfil its early promises and notes 'a disconnect between the increasingly banal applications of digital media in the "real world" and the favored objects of digital study in the academy' $(2003,181)$. But his is far from a lone voice. In fact, so eager are the new breed of teetotal new media analysts to throw cold water 
on the unthinking enthusiasms of the digi-disciples that they tend to shy away from making any strong claims at all about changes inaugurated by digital technologies. If, as Sconce says, the 'real world' applications of digital technology are 'banal,' then surely it is to the banal that we should be directing our attention. And what could be more banal than the ubiquitous digital snapshot cameras wielded at every birthday party and in front of every tourist attraction; what more commonplace than the presence of phone cameras at every celebrity sighting or public event? On these occasions, is it primarily the possibility of the manipulation of the image which is at stake? Surely, what matters more is the speed with which the image appears after it has been taken and the fact that its taker no longer makes use of a professional photofinisher. These are relatively new developments in relation to conventional snapshot photography, but not, of course, in relation to Polaroid image-making.

\section{Polaroid snapshot praxis}

In concentrating on the question of manipulation and the supposed changing 'trutheffect' of digital images, commentators have focused disproportionately on the finished image, setting aside the practices of making that have led to that image. My case here is that, as far as Polaroid and digital snapshot culture are concerned, the resultant image cannot be considered separately from the practice of its making. What, then, are the key features of Polaroid image-making which distinguish it from other forms of pre-digital photography? There are three?: 
1) Speed: the image appears in an 'instant'

2) The image develops itself: there is no need to have recourse to a private darkroom or professional developing company

3) Uniqueness of the print: the process provides no negative, and therefore is not easily subject to the normal photographic process of multiple reproduction ${ }^{8}$

The first and the second properties are shared with digitally-produced snapshots, while the third clearly is not. I will return to the third feature at the end of the article, but first I want to consider_the implications of the shared features. Speed and instantaneity are of course relative concepts: the first Polaroid prints were ready in a minute, and the standard SX-70 image takes perhaps four to five to stabilise completely. What is important is that the process takes a single step, in Land's vocabulary, eliminating the delay (of days, weeks, months) that had normally been the experience of the amateur snapshot photographer. As Polaroid ads enjoined possible users: 'Take and show party pictures while the fun's going on'; 'see results at once....with no intervening delay for processing. ${ }^{9}$ Amateur Polaroid and digital image-making could not be further apart in their technologies of production and dissemination, but the speed with which the image appears and the way in which it 'develops' inside the camera mean that the former nevertheless anticipates the latter as a practice and a cultural form. 
One way of gauging the implications of speed and the elimination of the darkroom is to measure Polaroid and digital against the classic model of amateur snapshot practice as outlined by Don Slater. In his analysis of the ways in which snapshot culture contributes to domestic ideology and practices of leisure-time,_Slater identifies a fundamental discontinuity. He notes the importance of the 'family album' as a device for regulating identity and ordering memory, citing a survey that found that ' 39 per cent of respondents rated their family photos as the possessions they treasure most and would least like to lose' $(1995,138)$. However, he goes on to observe that

this hypervaluation of the family album sits oddly with our actual use of photographs: the same piece of research indicated that 60 per cent of respondents and their families looked at their family snaps only once a year....Moreover, it is unclear how many people actually organise their photos into anything approximating a family album: most of them remain in the same envelopes in which the processing company returned them. Thus the family album...is hypervalued yet plays little part in everyday life. Taking pictures is a taken for granted part of leisure activities; but looking at them is marginal. (1995, 138-9)

Slater then substitutes the term using for looking, and argues that in consumer culture, although images are increasingly used at the domestic level in the form of thome entertainment,' the images we produce ourselves tend not to be used in a structured way. In this account, then, the snapshot only has an intermittent and retroactive value, reflected upon long after its making, if at all. 
As part of their push to bring the new generation of camera phones to the UK market, Sony Ericsson screened in 2005 a television advert that suggests a rather different snapshot praxis than the one outlined by Slater. Under the tag-line 'take your best shot - with a phone!,' the new Sony K750i was promoted by an improbably handsome young couple strolling along the side of a lake. He is on his phone, ignoring her, when she spots something and snatches the phone out of his hand. It is a water-lily and a dragon-fly. She gets them with the phone, shows him. He's unimpressed, quickly snapping the next manifestation of nature, a fish leaping to eat the dragonfly. He shows her the result, triumphant, she now downcast. Next a roaring grizzly materializes to devour the fish; he holds the camera paralysed, she pushes down on the button. Thus reconciled in their snapshooting partnership, with beatific looks they admire the resulting image of spontaneous nature, whilst an eagle comes down to lift the bear away. Here there is virtually no gap between 'taking' and 'using' the snapshot image, if we invoke Slater's distinction. Rather than a delayed or indefinitely postponed activity, the looking at the image has become coterminous with its taking. In terms of what Slater calls the 'use' of images, the digital snapshot has a potent life after its taking, potentially sent on as code to other phones, or as computer attachments. But the basic leisure activity here is surely the near simultaneous pairing of taking and showing, of production and consumption. 
According to Slater, writing before the explosion in affordable digital cameras and camera phones,

Taking photographs is itself structured... and is regarded as an intrinsic part of other leisure-event-structures: holidays, time-off, special occasions....Using photographs, however, does not fit the bill of leisure event, of a consumer practice or experience. $(1995,141)$

However, a good half-century before digital cameras closed the gap between taking and using in snapshot photography, Polaroid advertising campaigns had identified the potential for turning this very proximity into what Slater calls a 'structured activity.' Under the general slogan 'Pictures-in-a-minute,' Polaroid ads in the late 1940s claimed 'It's like taking your darkroom on location,' and emphasised that 'no other camera would give me a second chance like this,' meaning that if the picture didn't work out, you could take another immediately and improve on the result (see Figure 2). ${ }^{10}$ The ads also suggested possible activities that could be organised around the new product: 'hold photographic parties with a prize for the best picture made by a guest...enjoy your pictures with friends when they mean the most - while they are still news.' In 1950, the Polaroid copywriters came up with the catchphrase, 'You're the life of the party with a Polaroid Land Camera,' establishing the long association of the camera with social gatherings (see Figure 3). In its promotional materials, including the cover of the company's 1954 Annual Report, Polaroid invariably 
depicted an admiring group huddled around the recently-developed image which has been peeled away from the dead negative (see Figure 4). There they are, absorbed, like incipient digital camera users, in the immediacy of the image-making experience. They are simultaneously subjects and viewers of the photograph, a tableau mirrored in the image they are consuming. This sort of image of image-consumers became a genre in and of itself in all subsequent representation of Polaroid use.

As Nat Trotman has observed, most photographic theories 'presuppose a certain distance between the act of observing a photograph and the act of taking it,' but '[o]ver the course of a minute, a photograph does not concern remembering or forgetting. Rather, it plays between the lived moment and its reification as an object with its own physical presence. The party Polaroid is not so much an evocation of a past event as an instant fossilization of the present. (2002)

Trotman does not draw any conclusions about the broader cultural implications of photography becoming 'an instant fossilization of the present,', but we could tentatively note two developments in snapshot practice that have resulted from the collapsing of 'taking' into 'using'. On the one hand, there is_the potentially collective nature of the activity as signalled by the 'party snapshot'. A British reviewer of the SX-70 gave this encomium to the camera in 1976: 
Polaroid Land photography generally is a much more communal pursuit, since the photographer does not need to leave the scene with a promise to send the pictures on later. With the SX-70, that moment of revelation when the picture begins to appear, and which has made so many of us into photographers for life the first time we saw it, is no longer limited to the darkroom and may be shared with any who care to gather round and watch. (Crawley 1976, 1003)

The implications are not minor. With the elimination of the amateur's darkroom or the photo-finishing company, the sway of the 'expert' over the making of images is also eliminated. Equally, the 'communal pursuit' envisioned here may put paid to the roving eye of the isolated individual photographer, voyeuristic and detached, replaced instead by a more dispersed collective vision.

At the same time as it makes snapshot consumption a more immediate and potentially public activity, the elimination of the darkroom opens up to the casual amateur a range of private practices. Freedom from the monitory gaze of the photochemist means what might have been taboo now becomes picturable. Peggy Sealfon, author of a popular manual of instant photography euphemistically sums up this popular practice enabled by Polaroid:

No longer did picture-takers have to wait a week for local drugstore processing, and no longer did they have to be concerned about the film's contents passing 
under the scrutiny of the druggist's eye. Instant pictures of lovers and spouses became quite common. $(1983,6)$

The parallels with popular digital snapshooting should be self-evident, although it is a different sort of obscenity that has captured the most attention. Commenting balefully on the explosion in 'gadgetry of instant objectification,' the Retort collective read the continuous digital archiving of the present as a symptom of a 'crisis in time,' where no real reflection on the past is any longer possible: 'it has to be recorded, since experience without instant doubling is no experience at all. "Here's me third from the left at Thanksgiving in Abu Dhabi; and here's me on top of a pigpile of Terrorists"' (2005, 182-3). Retort imply that in the relentless drive to instantaneity the digital camera user hardly distinguishes between Thanksgiving and a pigpile, but surely one difference is that the image of a pigpile would never have been sent to a professional photo-finisher by the amateur snapshooter.

As for the death of Polaroid at the hands of digital, what I hope has become clear is that it is not simply a case of one technology being displaced by another. Polaroid technology may be fated to obsolescence, but as William Boddy has argued, 'digital imaging developed largely through a process of infiltrating existing signifying practices which are already embedded in a diverse set of highly developed cultural forms' $(2004,68)$. While there are clearly historical and technical discontinuities between the SX-70 and the camera phone, it is also the case that the modes of using 
the latter take shape in a cultural field in which there were already existing social practices based around the former. And while digital cameras, particularly in phones, have massively increased the recruitment levels of casual snapshot takers, this process had already been accelerated by Polaroid.

\section{Coda: Polaroid's digital after-life}

I argued at the start of this article that Tom Gunning brackets questions of practice in his discussion of the digital image. It could be argued that in my attention to practices of image-making I have effectively bracketed the question of the image. I said that the third defining feature of Polaroid photography is the uniqueness of the image, that it provides no negative for further mechanical reproduction. Clearly this is a major difference from the digital image, which is infinitely and effortlessly reproducible_in countless possible contexts. Whatever commonality there might be between the Polaroid and digital snapshots at the point of their making, they part company radically here. Indeed, this fact - the digital image's basis in binary code has led to a whole array of new practices at the level of the dissemination and circulation of photographic images after their making. ${ }^{11}$ In contrast, the Polaroid image is stubbornly attached to its material support in a way that even conventional negative-based photography never was. Certainly, an SX-70 Polaroid image can be scanned into a computer, but this is only ever a partially complete operation. When these pictures are scanned in, the built-in white frame, with its wider bottom edge, is invariably included in order to identify the Polaroid image as such. But this frame 
(the lower part, often used for writing on, houses the pod of developing reagent which bursts as film is ejected) is not strictly speaking part of the image, but rather part of the object. In fact, the SX-70 print is 'an image that is also a thing' (Schjeldahl 1987, 9), 'both sculptural and pictural,' (Van Lier 1983, xii) and any convergence with computers will always leave an untransmittable remainder, because, counter to the plural logic of technical reproducibility, the Polaroid is always only singular.

But the situation is by no means straightforward. While fewer and fewer Polaroid prints are being made as the technology gradually disappears, the distinctive white borders are experiencing a striking digital after-life, especially in advertising. Although promotions for products as varied as National Rail, Peugeot (Rugby World Cup, 2007), Manchester Tourist Board, Co-Operative Bank, and Virgin Megastore clearly have not used actual Polaroid technology to produce the images for their campaigns, these images have been enhanced after the fact with the iconic white borders in the simplest of Photoshop operations. The borders are then usually written on (digitally), just as popular practice dictated that the original prints would often be titled at the bottom. Just to drive home that the images of screenwriters in the ad for ScreenwritersStore.com are meant to be read as Polaroids, the simulated prints are 'stuck' to the background of the ad with digitally simulated cellotape. Why do these ads (but it is not just ads - an article in the Times Higher 4 June 2009 uses simulated Polaroids for purposes of illustration; The New York Times online regularly uses the white border for its picture stories) make use of simulated instant 
snapshots? Presumably because Polaroid prints are a useful shorthand for the photograph, any photograph, as a physical object. In each case, we are clearly meant to understand that these are actual prints - photos as objects - that we are looking at, and the Polaroid print, with its white border, leaves us in no doubt about this, whereas a (simulated) snapshot taken from a shoebox and scanned would not necessarily divulge its object-hood so self-evidently. In the National Rail ad promoting 'days out', there are nine 'Polaroid' images of a red-hatted gnome in different locations - at the seaside, in the Peaks, in front of a castle (see Figure 5). These days such photos would most likely be captured on a camera phone and circulated as digital files, and yet the advertisers choose an antiquated photo-format rather than showing the images, for example, in a series of phones. The ads are composed entirely on the basis of digital imaging technology, and yet they want us to see their images as if they were singular material objects and not just bits of code. The vernacular snapshot format alluded to by these ads is being gradually dematerialized with digital technology, and the digitally produced Polaroid border - a marker of non-convergence - suggests a lingering regret for the passing of the photo as material object. The simulated white border is, therefore, a kind of compensation for the absence of the photo as tangible and tactile.

The research for this article has been generously supported by grants from the Arts and Humanities Research Council UK and the British Academy. Thanks also to Tim Mahoney at the Baker Library, Harvard. 


\section{References}

Barthes, R., 1977. Image Music Text. London: Fontana.

Benjamin, W. 1999. Selected Writings: Volume 2, 1927-34. Cambridge, MA.: Belknap Press of Harvard University Press.

Boddy, William. 2004. New Media and popular imagination: Launcbing Radio, Television, and Digital Media in the United States. Oxford: Oxford University Press.

Buse, P. 2007. Photography Degree Zero: Cultural History of the Polaroid Image. new formations 62: 29-44.

Caldwell, J.T. 2003. Second-Shift Media Aesthetics: Programming, Interactivity, and User Flows. In New Media: Theories and Practices of Digitextuality, A. Everett and J.T. Caldwell, 127-44. London and New York: American Film Institute and Routledge.

Clarke, Graham. 1997. The Photograph. Oxford: Oxford University Press.

Columbus, N. 1999. Polaroid Milestones. In Innovation / Imagination: 50 Years of Polaroid Photography, ed. N. Columbus, 118-19. New York: Harry N. Abrams.

Crawley, G. 1976. SX-70 camera and film - A Review. British Journal of Photography 123, no. 46: 998-1003.

Deutsch, C.H. 2005. Big Picture Beyond Photos. New York Times, October 1, Section C4.

Dubois, P. 1990. L'acte photographique et autres essais, $2^{\text {nd }}$ ed. Brussels: Labor.

Everett, A., and Caldwell, J.T. 2003. Introduction: Issues in the Theory and Practice of Media Convergence. In New Media: Theories and Practices of Digitextuality, ed. 
A. Everett and J.T. Caldwell, xi-xxx. London and New York: American Film Institute and Routledge.

Goldsmith, A. 1991. Photos Always Lied. Popular Photography 98, no. 11: 68-75.

Gunning, T. 2008. What's the Point of an Index? Or, Faking Photographs. In Still Moving: Between Cinema and Photography, ed. K.Beckman and J. Ma, 23-40. Durham and London: Duke University Press.

Kember, S. 1996. 'The Shadow of the Object': photography and realism. Textual Practice 10, no. 1: 145-63.

Krasner, J. 2005a. Minnesota Firm to Acquire Polaroid. Boston Globe January 8, Section E1.

------. 2005b. Polaroid cuts R \&D, Digital Plans under new owner, Firm is little more than brand name. Boston Globe, August 2, Section C1.

Land, E. 1947. A New One-Step Photographic Process. Journal of the Optical Society of America 37, no.2: 61-77.

------. 1974. Absolute One-Step Photography. The Photographic Journal 114: 338-45.

Lister, M. 1995. Introductory Essay. In The Photographic Image in Digital Culture, ed. M. Lister, 1-26. London: Routledge.

Manovich, L. 2003. The Paradoxes of Digital Photography. In The Photography Reader, ed L. Wells, 240-49. London: Routledge.

Martin Kao, D. 1999. Edwin Land's Polaroid: A New Eye. In Innovation / Imagination: 50 Years of Polaroid Photography, ed. N. Columbus, 13-19. New York: Harry N. Abrams. 
Mitchell, W.J.T. 1992. The Reconfigured Eye: Visual Truth in the Post-photographic Era. Cambridge, Mass.: MIT Press.

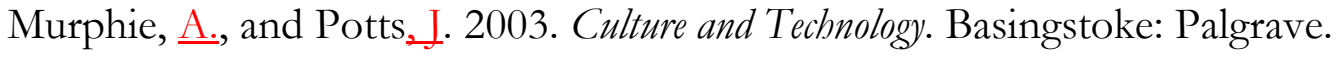

Osborne, P. 2003. Photography in an expanding field: Distributive unity and dominant form. In Where is the photograph?, ed. D. Green, 63-70. Brighton: Photoworks and Photoforum.

'Photo-Document Integration,' 1991. 1991 New Products and Technologies folder, 1991 Meeting of Stockholders information packet, May 7, 1991, Polaroid Corporation Collection, Baker Library Historical Collections, Harvard Business School.

Polaroid Corporation Annual Report, 1954.

Retort. 2005. Afflicted Powers: Capital and Spectacle in a New Age of War. London: Verso.

Robins, K. 1995. Will Image Move Still? In The Photographic Image in Digital Culture, ed. Martin Lister, 29-50. London: Routledge.

Rubinstein, D, and Sluis, K. 2008. A Life More Photographic: Mapping the Networked Image. Photographies 1, no. 1: 9-28.

Schjeldahl, P. 1987. The Instant Age. In Legacy of Light, ed. Constance Sullivan, 8-13. New York: Alfred A. Knopf.

Sconce, J. 2003. Tulip Theory. In New Media: Theories and Practice of Digitextuality, ed. A. Everett and J.T. Caldwell, 179-193. London and New York: American Film Institute and Routledge.

Sealfon, P. 1983. The Magic of Instant Photography. Boston: CBI Publishing. 
Slater, D. 1995. Domestic Photography and Digital Culture. In The Photographic Image in Digital Culture, ed. Martin Lister, 129-46. London: Routledge.

Tripsas, M., and Gavetti, G. 2000. Capabilties, Cognition, and Inertia: Evidence from Digital Imaging. Strategic Management Journal 21: 1147-61.

Trotman, N. 2002. The Life of the Party: the Polaroid SX-70 Land camera and instant film photography. Afterimage 29, no. 6: 10.

Van Lier, H. 1983. The Polaroid Photograph and the Body. In Stefan de Jaeger, xi-ixx. Brussels: Poot.

Warriner, W. 1980. Illuminations: Photography and Scientific Discovery. Close-Up 11, no. 2: 2-9.

\footnotetext{
${ }^{1}$ The author consulted in 2007 materials that Polaroid Corporation donated to Baker Library, Harvard Business School in 2006. The collection was largely unprocessed at the time this article was researched and written. The Polaroid archives will henceforth be cited as the Polaroid Corporation Collection.

${ }^{2}$ On the sell-off, see Krasner 2005a and Krasner 2005b.

${ }^{3}$ As early as 1980 the Polaroid in-house magazine, Close-Up, featured an article with a detailed discussion of 'Analog Versus Digital' (See Warriner 1980, 6). See Tripsas and Gavetti 2000 for an account of Polaroid's decline as a business. Tripsas and Gavetti claim that Polaroid suffered from 'organizational inertia in the face of radical technological change....despite early investments and leading-edge technical capability in areas related to digital imaging' (1148).

${ }^{4}$ The following all take issue with Mitchell as a central part of their arguments: Kember 1996; Lister 1995; Manovich 2003; Robins 1995. The complaint against Mitchell is fairly uniformly that he exaggerates the extent of change inaugurated by the digital and thereby grants too much historical agency to it. In other words, he is accused of technological determinism.

${ }^{5}$ See, for instance, Goldsmith 1991 or Manovich 2003, 244-5. Gunning 2008, 25-6 also returns to this point.
} 
${ }^{6}$ Kember 1996 articulates these objections very clearly, and is also good on 'the paradox of photography's fading but always mythical realism' (146). See also Lister 1995. Although the arguments made by Kember, Lister and others are vital to counteract the still powerful realist stance regarding the photographic image, they do not really progress beyond the ground-breaking case made by Roland Barthes in 1961 (see Barthes 1977). The subsequent chorus in the 1960s and 70s denouncing photography's 'effect of the real' is consummately summarized by Dubois 1990, 31-40.

7 These three properties were first outlined in Buse 2007, 37-8.

${ }^{8}$ Mainly due to demand from professional photographers, Polaroid introduced in 1961 Type 55 film, which produced a usable negative. Its film for snapshot purposes remained positive-only, and it is of course not possible to produce a negative from 'integral' SX-70 film.

${ }^{9}$ August 1949 and November 1951 campaigns in The Camera and Modern Photography.

${ }^{10}$ September 1949 and November 1949 campaigns in The Camera and U.S. Camera.

${ }^{11}$ See Rubinstein and Sluis for a survey of such practices and critical literature on them. 